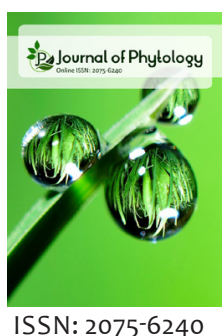

Received: June 11, 2020 Revised: August 15, 2020 Accepted: August 17, 2020 Published: September 15, 2020

*Corresponding author: Livia M. Negri

Email: negri.livia@inta.gob.ar

\section{Effect of different drying conditions on volatile compounds of Canelo pepper (Drimys winteri)}

\author{
Livia M. Negria*, Emiliano A. Spontón ${ }^{b}$, Oscar Salgadoc, Ana Sanchoa, and \\ Gabriela I. Denoyaa,d
}

anstituto Tecnología de Alimentos, Instituto Nacional de Tecnología Agropecuaria (INTA), Hurlingham (Buenos Aires), Argentina, ${ }^{b}$ Agencia de Extensión Rural de Usuahia, Instituto Nacional de Tecnología Agropecuaria (INTA), Ushuaia (Tierra del Fuego), Argentina, 'Laboratorio de Bromatología, Municipalidad de Ushuaia, Ushuaia (Tierra del Fuego), Argentina, ${ }^{d}$ Consejo Nacional de Investigaciones Científicas y Técnicas (CONICET), Argentina

\begin{abstract}
Canelo pepper is produced with the fruit of Drimys winteri (Winteraceae family). Driven by gourmet cuisine, this product is becoming increasingly in demand. The aim of this work was to study the effect of two drying conditions on the composition of the volatile compounds of Canelo pepper from Ushuaia forests (Argentina). Two treatments were evaluated. A mild drying (in a ventilated dryer, 2 days at $30^{\circ} \mathrm{C}$ ) that produced green pepper $(\mathrm{G})$ and a strong drying (on an unventilated stove 6 days at $43^{\circ} \mathrm{C}$ ), which produced brown pepper (B). Untreated samples were used as fresh control (F). The profile of the volatile compounds of Canelo pepper varied when the fruits were dried and also changed with the drying conditions. Besides, the milder treatment affected the volatile compounds from the pepper to a lesser extent than the stronger drying.
\end{abstract}

KEYWORDS: Canelo, volatile compounds, terpenes, drying, flavor

\section{INTRODUCTION}

Canelo pepper corresponds to a product made from the fruits of the species Drimys winteri (family Winteraceae) that grows as a shrub or tree in the Patagonian Andean Forests of Argentina and Chile [1]. These fruit, that contain aromatic and sapid substances, are used to season meals [2] and their consumption has been traditionally associated with medicinal properties. Moreover, the Canelo tree is sacred for the Mapuche people, an indigenous ethnic group from Argentina [3,4]. Additionally, Monsálvez et al. [5] have described the antifungal effect of Canelo associated with the presence of sesquiterpenes. In particular, unsaturated dialdehyde sesquiterpenes (polygodial and drimenol) are known for their antimicrobial activity and pungency $[6,7]$.

On the other hand, thermal processing of foods is based on the application of heat at a certain level for a particular length of time to inactivate microorganisms and enzymes to a targeted level in order to stabilize the product during subsequent storage [8]. Since all the reactions are accelerated at high temperatures, the quality (e.g., nutrient content, flavor, process-induced contaminants) of the product is (mostly) negatively affected [9]. In Chile, Canelo fruit are dried acquiring a brown coloration and in this form are commercialize as Southern Pepper [10]. In Argentina, two types of roasting of the fruit are made obtaining green and brown pepper, being the green, the most valued for its pungence [1]. Recent studies $[11,12,13]$ have been focused on the volatiles or flavor of black pepper; however, studies about the influences of drying methods on volatiles modification of spices are limited [14].

The hypothesis of this work was that the drying conditions applied to the Canelo fruit modify the composition of their volatile compounds. So, the aim of this study was to evaluate the effect of two drying conditions on the composition of volatile compounds (VOC) of these fruit collected from forests at the coast area of the Beagle Canal, Ushuaia, Argentina.

\section{MATERIALS AND METHODS}

\section{Pepper Samples and Treatment}

Fruit of Drymis winteri were harvested manually and subjected to two treatments. A batch, immediately after harvesting, was subjected to a mild drying treatment (MD) in a ventilated dryer for 2 days at $30^{\circ} \mathrm{C}$. This drying produced green fruits $(\mathrm{G})$. Another batch, processed after 24 hours of harvesting, was

Copyright: $\odot$ The authors. This article is open access and licensed under the terms of the Creative Commons Attribution License (http://creativecommons.org/licenses/by/4.0/) which permits unrestricted, use, distribution and reproduction in any medium, or format for any purpose, even commercially provided the work is properly cited. Attribution - You must give appropriate credit, provide a link to the license, and indicate if changes were made. 
subjected to a strong drying (SD) of 6 days at $43{ }^{\circ} \mathrm{C}$ in a stove without ventilation. This drying (SD) produced brown fruits (B). This darkening also occurs when the fruits are damaged during harvest, promoting enzymatic oxidations. In addition, samples without any treatment were analyzed as fresh control (F).

\section{Solid Phase Microextraction (SPME) Conditions}

Volatile compounds of samples were determined by SPME with a Divinylbenzene/Carboxen/Polydimethylsiloxane $(2 \mathrm{~cm}$ length; 50/30 $\mu \mathrm{m}$ coating thickness) fiber and a manual holder (Supelco Inc.Bellefonte, PA, USA). Two grams of ground fruit were immediately transferred into $10 \mathrm{ml}$ glass vials (Varian Inc, Argentina), which were hermetically covered and closed with aluminum caps and silicone/ Polytetrafluoroethylene (PTFE) septa (Sigma-Aldrich, Argentina) for analysis. Vials were placed in a dry heating block with magnetic agitation, with temperature control (Pierce Reacti-therme, Thermo Scientific) at $55 \pm 1{ }^{\circ} \mathrm{C}$ for $15 \mathrm{~min}$, and then exposed the fiber in the headspace for $15 \mathrm{~min}$. After this time, the fiber was retracted and taken to the injection port of the gas chromatograph (GC).

\section{VOC Analysis by Gas Chromatography-mass Spectrometry (GC-MS)}

The desorption of the VOC retained in the fiber was performed thermally at $220{ }^{\circ} \mathrm{C}$ for 0.5 minutes (splitless mode). A gas chromatographer equipped with a micro-capillary chromatographic column SLB-5-MS ( $15 \mathrm{~m} \times 0.10 \mathrm{~mm} \times 0.10 \mu \mathrm{m})$ and coupled to a mass spectrometer (MS) as a detector (Shimadzu QP-2010, Tokyo, Japan) was used for the separation and identification of compounds. Chromatographic conditions of the GC were: detector temperature: $220^{\circ} \mathrm{C}$; column temperature program, $30^{\circ} \mathrm{C}$ for $2 \mathrm{~min}, 5^{\circ} \mathrm{C} / \mathrm{min}$ to $150^{\circ} \mathrm{C}$, temperature that was kept for $5 \mathrm{~min}$ and $40{ }^{\circ} \mathrm{C} / \mathrm{min}$ to $290{ }^{\circ} \mathrm{C}$, temperature that was kept for $10 \mathrm{~min}$. The operating conditions of the MS were: ionization voltage, $70 \mathrm{eV}$; interface temperature, $300{ }^{\circ} \mathrm{C}$; scan mass range, 33 to $400 \mathrm{~m} / \mathrm{z}$; scanning speed, $2000 \mathrm{amu} / \mathrm{sec}$; carrier gas, helium $(0.62 \mathrm{~mL} / \mathrm{min})$. Peaks spectra were compared to information stored in the software's spectrum library (NIST, Version 2.0, 2002; NIST USA).

Experiences were conducted in triplicate.

\section{Statistical Analysis}

The percentage of the different groups of volatile compounds were compared for the three sample types (F, G, and B) of pepper, using ANOVA. The least significant difference (LSD) test (SPSS version 10.0, Chicago, USA) was used to detect statistically significant differences between the means.

\section{RESULTS AND DISCUSSION}

A total of 107 compounds belonging to the chemical groups of acids (1), alcohols (1), aldehydes (8), hydrocarbons (6), esters (6), ketones (4), terpenes (70), ethers (2) were identified in the Canelo pepper samples studied.
The predominant compounds in all the samples were terpenes $(>80 \%)$ and within them, the monoterpenes. Alcohols were the second major chemical compounds in Canelo pepper (2 to $4 \%$ ) (Table 1 ). In F pepper, the predominant alcohol was 3 -octanol that is associated with soil, moldy, herbal odor [15]. G pepper presented the lowest value of alcohols (2.23\%) and the most important compound corresponding to this type of chemical compounds in these fruit was 2-ethylhexanol which is associated with the flavor of green and roses [16]. In B pepper, the predominant alcohol was butane-2,3-diol, occupying the fourth place among all the volatiles identified in this sample. This alcohol can be generated by the oxidation of lipids [17] and also by fermentation and contributes to the soft, sweet and balsamic flavors [18]. Among the acids, only acetic acid was identified in the $\mathrm{G}$ and $\mathrm{B}$ samples. $\mathrm{G}$ had the lowest value $(0.51 \pm 0.04 \%)$ and $\mathrm{B}$, the highest value $(1.72 \pm 0.61 \%)$. Acetic acid is an oxidation product of ethanol [19]. Then, this fact could explain the presence of ethanol in fresh pepper and acetic acid only in dried samples. B pepper had the highest percentage of aldehydes (Figure 1) (2.44\%). The presence of hexanal in all the samples is worth to be highlighted (Table 1). This compound represents a low proportion of the volatiles in $\mathrm{F}$ pepper but the amount of it is increased as long as the treatment of drying becomes more severe. Although hexanal has been described in peppers and has been associated with green and spicy flavors [20], in high concentrations is a VOC that has been associated with the development of undesirable flavors. The content of hexanal, which is the major breakdown product oxidation of linoleic acid (LA), an $n-6$, polyunsaturated fatty acid (PUFA), has

Table 1: Alcohols and aldehydes (arbitrary area units, $\%^{1}$ ) identified in the volatile fraction of fresh, mild dried (green) and strong dried (brown) Canelo pepper.

\begin{tabular}{|c|c|c|c|}
\hline Compounds & Fresh & Green & Brown \\
\hline \multicolumn{4}{|l|}{ Alcohols } \\
\hline Ethanol & $1.35 \pm 0.14$ & nd & nd \\
\hline 1-Pentanol & nd & $0.08 \pm 0.01$ & nd \\
\hline 2-Heptanol & $0.10 \pm 0.02$ & nd & nd \\
\hline 3-0ctanol & $1.99 \pm 0.48$ & nd & nd \\
\hline 2-Nonen-1-ol-2-methyl & $0.30 \pm 0.02$ & $0.33 \pm 0.05$ & nd \\
\hline 2-Ethylhexanol & nd & $1.67 \pm 0.43$ & nd \\
\hline 2-Methyl-1-octanol & nd & $0.05 \pm 0.01$ & nd \\
\hline Butane-2,3-diol & nd & nd & $4.24 \pm 0.53$ \\
\hline $\begin{array}{l}\text { 2-Isopropyl-5-methyl-1- } \\
\text { heptanol }\end{array}$ & nd & nd & $0.03 \pm 0.00$ \\
\hline 4-Allyl-2-methoxyphenol & $0.21 \pm 0.06$ & $0.10 \pm 0.02$ & nd \\
\hline \multicolumn{4}{|l|}{ Aldehydes } \\
\hline 3-Methylbutanal & $0.14 \pm 0.06$ & nd & $0.08 \pm 0.03$ \\
\hline 2-Methylbutanal & $0.08 \pm 0.02$ & nd & $0.18 \pm 0.02$ \\
\hline Pentanal & nd & $0.14 \pm 0.02$ & nd \\
\hline Hexanal & $0.26 \pm 0.01$ & $0.56 \pm 0.11$ & $1.75 \pm 0.82$ \\
\hline (E)-2-Hexenal & $0.02 \pm 0.00$ & nd & nd \\
\hline Benzaldehyde & $0.01 \pm 0.00$ & nd & nd \\
\hline (E)-2-Heptenal & nd & nd & $0.10 \pm 0.00$ \\
\hline$\alpha$-Campholenaldehyde & nd & nd & $0.34 \pm 0.04$ \\
\hline
\end{tabular}

${ }^{1}$ Arbitrary area units (\%) express the percentage ratio between the area value, in arbitrary area units, of the peak of the compound and the value of the total area of the volatile fraction of the sample. Data are expressed as means \pm standard deviations $(n=3)$. nd: Not detected. 


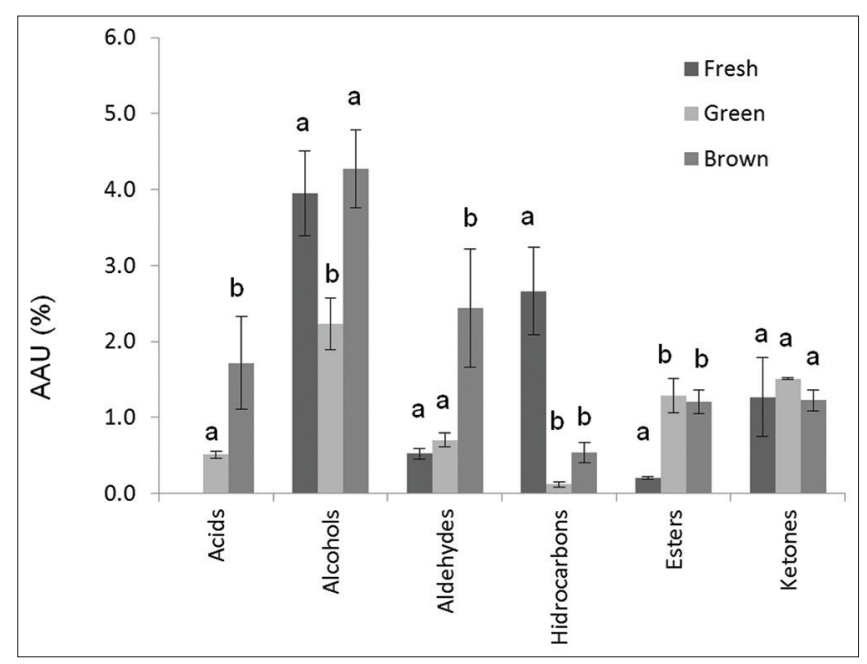

Figure 1: Acids, alcohols, aldehydes, hydrocarbons, esters and ketones (arbitrary area units, \%) identified in the volatile fraction of fresh, mild dried (green) and strong dried (brown) Canelo pepper. Arbitrary area units (\%) express the percentage ratio between the area value, in arbitrary area units, of the peak of the type of compounds and the value of the total area of the volatile fraction of the sample. Error bars correspond to standard deviations. Values with different letters are significantly different $(\mathrm{P}<0.05)$

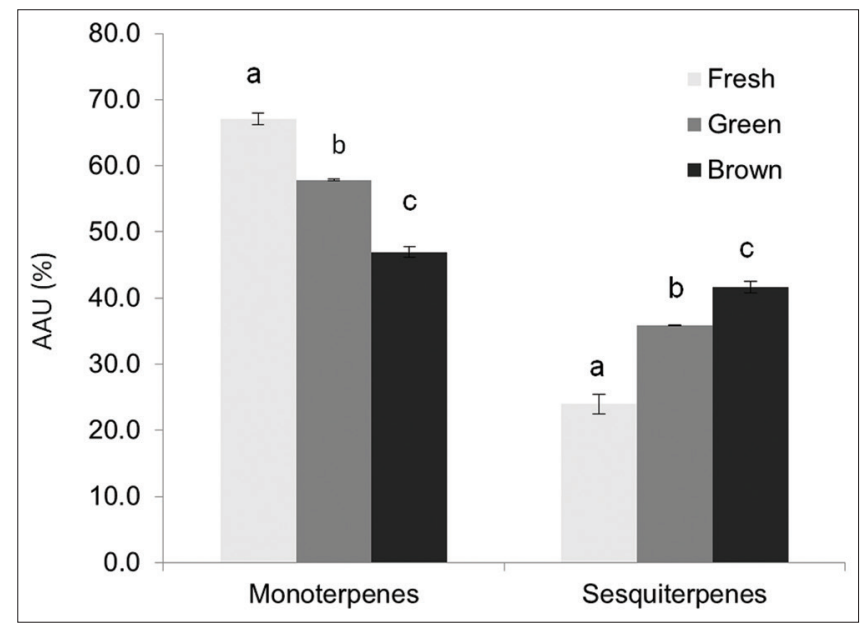

Figure 2: Monoterpenes and sesquiterpenes (arbitrary area units, \%) identified in the volatile fraction of fresh, mild dried (green) and strong dried (brown) Canelo pepper. Arbitrary area units (\%) express the percentage ratio between the area value, in arbitrary area units, of the peak of the type of compounds and the value of the total area of the volatile fraction of the sample. Error bars correspond to standard deviations. Values with different letters are significantly different $(\mathrm{P}<0.05)$

been used to follow the course of lipid oxidation and offflavor development in foods. A "cardboard-like" off-flavor is frequently associated with dehydrated milk products. This effect is highly correlated with the concentration of hexanal at the headspace of the product $[21,22]$. A previous work has described that Canelo pepper contains a high amount of PUFA among its fatty acids [1]. This could explain the greater amount of hexanal found in B pepper, which had been subjected to more severe drying conditions than the green one. Besides, F pepper had the lowest amount of hexanal.
Table 2: Hydrocarbons, esters and ketones (arbitrary area units, $\%^{1}$ ) identified in the volatile fraction of fresh, mild dried (green) and strong dried (brown) Canelo pepper

\begin{tabular}{|c|c|c|c|}
\hline Compounds & Fresh & Green & Brown \\
\hline \multicolumn{4}{|l|}{ Hidrocarbons } \\
\hline Toluene & $1.33 \pm 0.29$ & nd & nd \\
\hline Annulene & $0.10 \pm 0.02$ & nd & nd \\
\hline (5z)-5-undecen-3-yne & nd & $0.12 \pm 0.03$ & nd \\
\hline Octadecane & nd & nd & $0.18 \pm 0.07$ \\
\hline Heptadecane & nd & nd & $0.16 \pm 0.06$ \\
\hline \multicolumn{4}{|l|}{ Esters } \\
\hline Methyl 2-methylbutanoate & $0.02 \pm 0.00$ & nd & nd \\
\hline 3-Methylbutyl acetate & $0.05 \pm 0.01$ & $0.17 \pm 0.01$ & $0.14 \pm 0.05$ \\
\hline Methyl 2-methyloctanoate & $0.12 \pm 0.03$ & $0.42 \pm 0.05$ & $0.55 \pm 0.22$ \\
\hline 3-0ctyl acetate & nd & $0.71 \pm 0.18$ & $0.51 \pm 0.09$ \\
\hline \multicolumn{4}{|l|}{ Ketones } \\
\hline 2-Propanone & nd & $0.86 \pm 0.04$ & $0.18 \pm 0.06$ \\
\hline 2-Heptanone & $0.03 \pm 0.01$ & nd & nd \\
\hline 3-Octanone & $1.37 \pm 0.71$ & $0.65 \pm 0.03$ & nd \\
\hline 3-Hydroxy-2-butanone & nd & nd & $1.04 \pm 0.08$ \\
\hline
\end{tabular}

${ }^{1}$ Arbitrary area units (\%) expresses the percentage ratio between the area value, in arbitrary area units, of the peak of the compound and the value of the total area of the volatile fraction of the sample. Data are expressed as means \pm standard deviations $(n=3)$. nd: Not detected.

Table 3: Monoterpenes (arbitrary area units, $\%^{1}$ ) identified in the volatile fraction of fresh, mild dried (green) and strong dried (brown) Canelo pepper

\begin{tabular}{|c|c|c|c|}
\hline Compounds & Fresh & Green & Brown \\
\hline \multicolumn{4}{|l|}{ Monoterpenes } \\
\hline$\alpha$-Thujene & $2.79 \pm 0.47$ & $0.40 \pm 0.01$ & $0.28 \pm 0.07$ \\
\hline$\alpha$-Pinene & $9.26 \pm 2.18$ & $11.30 \pm 0.55$ & $17.58 \pm 1.28$ \\
\hline Camphene & $1.10 \pm 0.10$ & $0.92 \pm 0.08$ & $1.80 \pm 0.52$ \\
\hline$\beta$-Pinene & $11.37 \pm 0.69$ & $11.41 \pm 0.40$ & $0.64 \pm 0.18$ \\
\hline Myrcene & $6.70 \pm 1.25$ & $4.71 \pm 0.79$ & $2.69 \pm 0.50$ \\
\hline$\alpha$-Phellandrene & $1.39 \pm 0.31$ & $1.96 \pm 0.31$ & nd \\
\hline 3-Carene & nd & $0.49 \pm 0.01$ & $2.22 \pm 0.13$ \\
\hline$\alpha$-Terpinene & $1.26 \pm 0.28$ & $0.60 \pm 0.12$ & $0.98 \pm 0.39$ \\
\hline$p$-Cymene & $2.43 \pm 1.05$ & $1.82 \pm 0.13$ & nd \\
\hline Limonene & $5.10 \pm 0.57$ & $4.76 \pm 0.22$ & $4.19 \pm 1.31$ \\
\hline$\alpha$-0cimene & $8.01 \pm 0.88$ & $7.82 \pm 0.10$ & $3.57 \pm 1.07$ \\
\hline$\beta$-0cimene & $0.50 \pm 0.11$ & $0.45 \pm 0.03$ & nd \\
\hline$\gamma$-Terpinene & $2.74 \pm 0.77$ & $1.30 \pm 0.25$ & $3.86 \pm 0.54$ \\
\hline cis-Sabinene hydrate & $0.08 \pm 0.02$ & $0.25 \pm 0.11$ & $0.29 \pm 0.14$ \\
\hline (+)-4-Carene & $0.57 \pm 0.40$ & $0.69 \pm 0.01$ & $0.65 \pm 0.24$ \\
\hline Fenchone & $0.33 \pm 0.11$ & $5.50 \pm 0.04$ & nd \\
\hline Linalool & $7.88 \pm 0.16$ & $0.35 \pm 0.07$ & $5.26 \pm 1.55$ \\
\hline trans-allo-0cimene & nd & $0.33 \pm 0.02$ & nd \\
\hline Camphor & $0.90 \pm 0.17$ & $0.07 \pm 0.01$ & $0.20 \pm 0.01$ \\
\hline trans-Pinocarveol & nd & $0.62 \pm 0.04$ & $0.07 \pm 0.01$ \\
\hline Borneol & $1.32 \pm 0.13$ & $0.15 \pm 0.00$ & $0.36 \pm 0.07$ \\
\hline Terpinen-4-ol & $0.82 \pm 0.22$ & $1.02 \pm 0.08$ & $0.25 \pm 0.01$ \\
\hline$\alpha$-Terpinol & $2.23 \pm 0.56$ & $0.03 \pm 0.00$ & $0.43 \pm 0.15$ \\
\hline Verbenone & nd & $0.09 \pm 0.01$ & nd \\
\hline Nerol & $0.24 \pm 0.06$ & $0.75 \pm 0.12$ & $0.07 \pm 0.02$ \\
\hline trans-Carveol & nd & nd & $0.08 \pm 0.03$ \\
\hline Dehydro-p-cymene & nd & nd & $0.12 \pm 0.00$ \\
\hline
\end{tabular}

Arbitrary area units (\%) expresses the percentage ratio between the area value, in arbitrary area units, of the peak of the compound and the value of the total area of the volatile fraction of the sample.Data are expressed as means \pm standard deviations $(n=3)$. nd: Not detected.

Hydrocarbons represented a relatively important group in $\mathrm{F}$ pepper (Figure 1) which presented the highest amount of compounds of this group $(2.66 \%)$. The most important compound was 
toluene (Table 2), only detected in F samples. This aromatic hydrocarbon has been described in other plant species [20]. On the other hand, F pepper had the lowest amount of esters $(0.20 \%)$ (Figure 1). Four esters were identified in the samples analyzed (Table 2). Esters of acetic and octanoic acids with butanol and methanol alcohols were found. The compound 3-methylbutyl acetate was identified in all the samples and has been associated with the flavor of fruits, especially banana [19]. The three types of pepper did not differ in the total content of compounds from the ketone group (Figure 1). Within this group, four compounds were identified in the samples analyzed (Table 2). In F pepper, the main ketone was 3-octanone, which was not detected in samples subjected to drying treatment. A similar situation was observed in the drying of common pepper (from Piper nigrum) [20]. The presence of 3-octanone within the volatile compounds of a product is associated with butter, herbaceous and mold flavor [16]. In both $\mathrm{G}$ and $\mathrm{B}$ pepper, the presence of 2-propanone was detected. This compound has previously been described in other foods as a result of processing [23] and is characterized by imparting spicy flavor [16]. The 3-hydroxy-2-butanone was the predominant ketone observed in B pepper, this compound contributes to the flavor with notes of butter, cream and green pepper [16].

The compounds of the ether group were only identified in $\mathrm{F}$ pepper with amounts that were less than $1 \%$ (1-methoxy2-methylbenzene y bornyl acetate). These compounds are associated with floral, green, herbaceous flavors [16]. Terpenes showed the largest diversity of compounds in this study and the three types of pepper differed in their content. Szöke, Lemberkovics, and Kursinszki [24] described that the peppery odor of pepper is due to $1-3.5 \%$ of an essential oil rich in terpenoid. B pepper had the lowest percentage

Table 4 : Sesquiterpenes (percentage of arbitrary area units ${ }^{1}$ ) identified in the volatile fraction of fresh, mild dried (green) and strong dried (brown) Canelo pepper

\begin{tabular}{|c|c|c|c|}
\hline Compounds & Fresh & Green & Brown \\
\hline \multicolumn{4}{|l|}{ Sesquiterpenes } \\
\hline Bicicloelemene & nd & $0.37 \pm 0.06$ & $0.06 \pm 0.02$ \\
\hline$\alpha$-Cubebene & nd & $1.42 \pm 0.04$ & $2.50 \pm 0.72$ \\
\hline Eugenol & nd & nd & $0.11 \pm 0.04$ \\
\hline$\alpha$-Copaene & $0.69 \pm 0.07$ & $2.20 \pm 0.17$ & $3.40 \pm 0.23$ \\
\hline$\beta$-Bourbonene & $0.28 \pm 0.06$ & $0.35 \pm 0.00$ & $0.35 \pm 0.07$ \\
\hline$\beta$-Elemene & $1.12 \pm 0.31$ & $1.42 \pm 0.21$ & $1.46 \pm 0.00$ \\
\hline$\gamma$-Elemene & $0.17 \pm 0.05$ & nd & nd \\
\hline$\alpha$-Gurjunene & $2.41 \pm 0.32$ & $1.55 \pm 1.02$ & $2.50 \pm 0.08$ \\
\hline$\alpha$-trans-Bergamotene & $0.57 \pm 0.11$ & nd & $0.84 \pm 0.05$ \\
\hline$\beta$-Caryophyllene & $3.07 \pm 0.31$ & $1.49 \pm 0.10$ & $4.70 \pm 0.48$ \\
\hline$\beta$-Cubebene & nd & $0.38 \pm 0.06$ & $0.32 \pm 0.01$ \\
\hline Aromadendrene & $1.23 \pm 0.26$ & $0.67 \pm 0.23$ & $1.90 \pm 0.11$ \\
\hline$\alpha$-Humulene & $1.42 \pm 0.20$ & nd & nd \\
\hline Farnesol & nd & $2.02 \pm 0.30$ & $2.55 \pm 0.87$ \\
\hline allo- Aromadendrene & nd & $1.61 \pm 0.13$ & nd \\
\hline$\gamma$-Gurjunene & sd & $0.70 \pm 0.07$ & $0.59 \pm 0.16$ \\
\hline Germacrene D & $1.59 \pm 0.33$ & $2.98 \pm 0.53$ & $1.75 \pm 0.01$ \\
\hline Selinene & nd & $0.19 \pm 0.07$ & $1.73 \pm 0.22$ \\
\hline Bicyclogermacrene & $2.92 \pm 0.24$ & $4.43 \pm 0.05$ & nd \\
\hline Shyobunone & $1.05 \pm 0.07$ & nd & $1.23 \pm 0.05$ \\
\hline$\beta$-Bisabolene & nd & $2.54 \pm 0.17$ & $2.99 \pm 0.38$ \\
\hline$\delta$-Cadinene & $1.08 \pm 0.21$ & $1.27 \pm 0.19$ & nd \\
\hline Cadina-1.4-diene & nd & $0.37 \pm 0.01$ & $0.50 \pm 0.04$ \\
\hline$\alpha$-Murolene & nd & $0.26 \pm 0.05$ & nd \\
\hline Nerolidol & nd & $0.58 \pm 0.10$ & $1.26 \pm 0.08$ \\
\hline Palustrol & nd & $0.15 \pm 0.03$ & $0.12 \pm 0.04$ \\
\hline Spathulenol & nd & $0.26 \pm 0.02$ & $0.49 \pm 0.07$ \\
\hline$\beta$-Eudesmol & $0.50 \pm 0.04$ & $0.66 \pm 0.09$ & $0.40 \pm 0.09$ \\
\hline Caryophyllene oxide & $0.79 \pm 0.08$ & $2.27 \pm 0.09$ & $2.04 \pm 0.16$ \\
\hline Viridiflorol & $0.08 \pm 0.02$ & $0.12 \pm 0.01$ & $0.11 \pm 0.04$ \\
\hline$\gamma$-Eudesmol & $0.56 \pm 0.04$ & $0.64 \pm 0.03$ & $0.85 \pm 0.23$ \\
\hline Cyclosativene & nd & $0.07 \pm 0.01$ & nd \\
\hline$\alpha$-Eudesmol & $0.54 \pm 0.07$ & $0.90 \pm 0.17$ & $0.52 \pm 0.09$ \\
\hline$\alpha$ Elemol & $0.10 \pm 0.04$ & $0.24 \pm 0.05$ & $0.11 \pm 0.04$ \\
\hline Carotol & nd & $0.12 \pm 0.02$ & $0.02 \pm 0.01$ \\
\hline Drimenol & $0.50 \pm 0.10$ & $0.65 \pm 0.16$ & $0.61 \pm 0.00$ \\
\hline Nootkatone & nd & nd & $0.35 \pm 0.09$ \\
\hline$\alpha$-Cubebene & $0.96 \pm 0.14$ & nd & nd \\
\hline 2,2,7,7-Tetramethyltricyclo[6.2.1.0(1,6)]undec-4-en-3-one & $0.13 \pm 0.04$ & nd & nd \\
\hline$\beta$-Farnesene & nd & nd & $2.26 \pm 0.45$ \\
\hline$\alpha$-Calacorene & nd & nd & $0.63 \pm 0.13$ \\
\hline
\end{tabular}

${ }^{1}$ Arbitrary area units (\%) expresses the percentage ratio between the area value, in arbitrary area units, of the peak of the compound and the value of the total area of the volatile fraction of the sample. Data are expressed as means \pm standard deviations $(n=3)$. nd: Not detected. 
of these compounds (88.6\%) and $\mathrm{G}$ pepper the highest $(93.61 \%)$ (Figure 2$)$. Considering the different treated peppers, $\mathrm{F}$ pepper had the highest percentage of monoterpenes $(67 \%)$ while B pepper had the lowest (47\%) percentage of these compounds. On the other hand, B pepper had the highest percentage of sesquiterpenes ( $42 \%$ ) while $\mathrm{F}$ pepper had the lowest $(24 \%)$ percentage of these compounds. These results could be explained by the fact that terpenoids in samples might be directly produced or converted from an initial product to sesquiterpenes or monoterpenes by oxidation, dehydrogenation and other reaction during the processing [25].

Table 3 shows the 27 monoterpenes identified in the Canelo pepper samples. $\beta$-pinene and $\alpha$-pinene resulted in the predominant compounds in $\mathrm{F}$ pepper (11.37 and $9.26 \%$, respectively) and $\mathrm{G}$ pepper (11.41 and $11.30 \%$, respectively). Flavour descriptors of $\beta$-pinene are dry-woody, pine-like, resinous-terpene-like and spicy [26]. In B pepper, the main monoterpene was $\alpha$-pinene (17.54\%) followed by linalool. These monoterpenes impart notes of pine, wood and resin flavor $[27,16]$. These results are consistent with Barrero et al. [28] who analyzed the composition of the essential oil of D. winteri wood. Cicció [29] and Monsálvez et al [5] also reported the presence of the $\beta$-pinene and $\alpha$-pinene but in essential fruit oils. The high proportion of $\beta$-pinene in pepper $F$ and $G$ and almost the absence in pepper $B$, was the main difference observed in the monoterpene composition of the samples. It is worth mentioning the presence of $\alpha$-ocimene in the $F$ and $G$ pepper in the third place of importance. This compound has not been reported in the essential oil of Canelo [28,29] and imparts fruity and wet notes [16]. Table 4 shows the 41 sesquiterpenes identified in the Canelo pepper samples. $\beta$-caryophyllene was the predominant compound identified in both $\mathrm{F}$ and $\mathrm{B}$ pepper (3.07\% and $4.70 \%$, respectively). The presence of this compound was previously reported by Cicció [29] and Barrero et al. [28]. On the other hand, the predominant sesquiterpene in $\mathrm{G}$ pepper was bicyclogermacrene $(4.43 \%)$. This compound has not been reported in previous studies and it contributed to green and wood [16].

It is important to highlight among the sesquiterpenes identified, the presence of drimenol. A compound that was first identified in 1994 in Drimys winteri. Unsaturated dialdehyde sesquiterpenes (polygodial and drimenol) are known for their antimicrobial activity and its pungence [6,7]. They have been described as compounds used by the plant to distract some insects [30], showing allelopathic effects $[31,32,33]$. Several authors reported their presence in different species of the Winteraceae family $[34,35,32,36,37]$. This compound was identified in F, G and $B$ pepper (Table 4). Unsurprisingly, the concentration of drimenol was lower than those reported in oil [29].

\section{CONCLUSIONS}

The results obtained in this work indicated that the composition of volatile compounds in Canelo pepper was modified by the heat treatment to which it was subjected. Fresh pepper and green pepper had a higher concentration of monoterpenes, (especially $\beta$-pinene) than brown toasted pepper. These results could explain the increased preference for the consumption of green pepper. The amounts of sesquiterpenes and aldehydes (especially hexanal) were greater in the brown pepper than in the green toasted one and the lowest concentration of these compounds were observed in fresh pepper. Brown pepper showed VOC compatible with fatty acid oxidation. On the other hand, the presence of drimenol was not affected by the drying treatments. It was detected in the three types of pepper evaluated. Subsequent sensorial analysis would be necessary to intensify the relationship between the composition and the flavor and off-flavor characteristics of pepper.

\section{ACKNOWLEDGMENTS}

This work was partially financed by the Project "Strategies for the agricultural and forestry development of the geographic area of the large island of Tierra del Fuego". We would like to grateful to Fabio Ariel Grimal and all the workers from the Laboratory of Food Science of the Ushuaia Municipality, to Enrique E. Livraghi from INTA Tierra del Fuego and all the team from the agricultural extension unit INTA Ushuaia.

\section{Conflict of Interest}

All authors declare that there is no conflict of interest.

\section{REFERENCES}

1. Spontón E, Salgado O, Cunzolo S, Rossetti L, Rizzo S, Denoya G, Chamorro V, Guidi S, Pazos A. Effect of different drying conditions on the nutritional composition of the Cinnamon fruit (Drymis winteri). VII Congreso Internacional de Ciencia y Tecnología de Alimentos (CICYTAC 2018), Córdoba, Argentina. 2018.

2. Cárcamo Muñoz, P. J. Estrategía de negocio para la comercialización de productos gourmet australes innovadores. http://repositorio. uchile.cl/handle/2250/116299, (accessed 8 june, 2020)

3. Gonzáles SB, Morales S. Plantas medicinales utilizadas en comunidades rurales del Chubut, Patagonia-Argentina. Latin American and Caribbean Bulletin of Medicinal and Aromatic Plants. 2004; 3(3): 58-62.

4. Munoz-Concha D, Vogel H, Yunes R, Razmilic I, Bresciani L, Malheiros A. Presence of polygodial and drimenol in Drimys populations from Chile. Biochemical Systematics and Ecology; 2007: 35(7), 434-438.

5. Monsálvez M, Zapata N, Vargas M, Berti M, Bittner M, Hernández V. Antifungal effects of $n$-hexane extract and essential oil of Drimys winteri bark against Take-All disease. Industrial Crops and Products. 2010; 31(2): 239-244.

6. Anke H, Sterner O. Comparison of the antimicrobial and cytotoxic activities of twenty unsaturated sesquiterpene dialdehydes from plants and mushrooms. Planta Medica. 1991; 57(04): 344-346.

7. Jonassohn M. Sesquiterpenoid unsaturated dialdehydes: Structural properties that affect reactivity and bioactivity. Lund University: Lund, Sweden; 1996: ISBN 91-628-2215-2.

8. Awuah, G., Ramaswamy, H., \& Economides, A. Thermal processing and quality: Principles and overview. Chemical Engineering and Processing: Process Intensification; 2007: 46(6), 584-602.

9. Kebede BT, Grauwet T, Tabilo-Munizaga G, Palmers S, Vervoort L, Hendrickx M, Van Loey A. Headspace components that discriminate between thermal and high pressure high temperature treated green vegetables: identification and linkage to possible process-induced chemical changes. Food Chemistry. 2013; 141(3): 1603-1613.

10. Varas P. Pimienta Nativa Gourmet. Informe Técnico final (09C5-5393, http://fdi.corfo ), 3 pp. 2010.

11. Jeleń HH, Gracka A. Analysis of black pepper volatiles by solid phase microextraction-gas chromatography: A comparison of terpenes 
profiles with hydrodistillation. Journal of Chromatography A. 2015; 1418: 200-209.

12. Silvis I, Luning $P$, Klose $N$, Jansen $M$, van Ruth $S$. Similarities and differences of the volatile profiles of six spices explored by Proton Transfer Reaction Mass Spectrometry. Food Chemistry. 2019; 271: 318-327.

13. van Ruth SM, Silvis IC., Ramos ME, Luning PA, Jansen M, Elliott CT, Alewijn MA cool comparison of black and white pepper grades. Food Science and Technology. 2019; 106: 122-127.

14. Jayatunga G, Amarasinghe B. Drying kinetics, quality and moisture diffusivity of spouted bed dried Sri Lankan black pepper. Journal of Food Engineering. 2019; 263: 38-45.

15. Luebke, W. The good scents company. http://www. thegoodscentscompany.com/index.html (accessed 19 december, 2018).

16. FEMA. Flavor \& Extract Manufacturers Assoc.. https://www. femaflavor.org/flavor-library (accessed 19 december, 2018)

17. Zeng Z, Zhang H, Chen JY, Zhang T, Matsunaga R. Direct extraction of volatiles of rice during cooking using solid-phase microextraction. Cereal Chemistry. 2007; 84(5): 423-427.

18. Ajarayasiri J, Chaiseri S. Comparative study on aroma-active compounds in Thai, black and white glutinous rice varieties. Kasetsart Journal (Natural Science). 2008; 42(4): 715-722.

19. National Center for Biotechnology Information, N. PubChem Compound Database; CID=31276. https://pubchem.ncbi.nlm.nih. gov/compound/31276 (accessed Dec 20, 2018).

20. Luning PA, de Rijk T, Wichers HJ, Roozen JP. Gas chromatography, mass spectrometry, and sniffing port analyses of volatile compounds of fresh bell peppers (Capsicum annuum) at different ripening stages. Journal of Agricultural and Food Chemistry. 1994; 42(4): 977-983.

21. Chávez-Servín JL, Castellote Al, López-Sabater MC. Volatile compounds and fatty acid profiles in commercial milk-based infant formulae by static headspace gas chromatography: Evolution after opening the packet. Food Chemistry. 2008; 107(1): 558-569.

22. Ulberth $F$, Roubicek $D$. Monitoring of oxidative deterioration of milk powder by headspace gas chromatography. International Dairy Journal.1995; 5(6): 523-531.

23. Attokaran, M. Natural food flavors and colorants: John Wiley \& Sons. 2017.
24. Szőke É, Lemberkovics É, Kursinszki L. Alkaloids derived from lysine: piperidine alkaloids. Natural Products: Phytochemistry, Botany and Metabolism of Alkaloids, Phenolics and Terpenes. 2013; 303-341.

25. Korkmaz, A., Hayaloglu, A. A., \& Atasoy, A. F. Evaluation of the volatile compounds of fresh ripened Capsicum annuum and its spice pepper (dried red pepper flakes and isot). LWT-Food Science and Technology; 2017: 84, 842-850

26. Ramawat KG, Mérillon J-M. Natural products: phytochemistry, botany and metabolism of alkaloids, phenolics and terpenes: Springer. 2013.

27. Acree T. Flavornet and human odor space. http://www. flavornet. org/flavornet. html. 2004

28. Barrero A, Herrador M, Arteaga P, Lara A, Cortes M. Chemical composition of the essential oil from Drimys winteri Forst. wood. Journal of Essential Oil Research. 2000; 12(6): 685-688.

29. Cicció JF. Aceites esenciales de las hojas y de los frutos verdes de Drimys granadensis (Winteraceae). Revista de Biología Tropical. 1996; 29-33.

30. Van Beek T, De Groot A. Terpenoid antifeedants, part I. An overview of terpenoid antifeedants of natural origin. Recueil des Travaux Chimiques des Pays-Bas. 1986; 105(12): 513-527.

31. Fujita K-I, Kubo I. Synergism of polygodial and trans-cinnamic acid on inhibition of root elongation in lettuce seedling growth bioassays. Journal of Chemical Ecology. 2003; 29(10): 2253-2262.

32. Malheiros A. Estudos químicos farmacológicos e alelopáticos das espécies Drimys angustifólia e Drimys brasiliensis (Winteraceae). 2001.

33. Malheiros A, Cechinel Filho V, Schmitt CB, Santos AR, Scheidt C Calixto JB, Yunes RAA. sesquiterpene drimane with antinociceptive activity from Drimys winteri bark. Phytochemistry. 2001; 57(1):103-107.

34. Brown GD. Drimendiol, a sesquiterpene from Drymis winterii. Phytochemistry.1994; 35(4). 975-977.

35. Dragar VA, Garland SM, Menary RC. Investigation of the variation in chemical composition of Tasmannia lanceolata solvent extracts. Journal of Agricultural and Food Chemistry. 1988; 46(8): 3210-3213.

36. McCallion RF, Cole A, Walker J, Blunt J, Munro M. Antibiotic substances from New Zealand plants. Planta Medica. 1982; 44(03): 134-138.

37. Muñoz O. Plantas medicinales de uso en Chile: Química y Farmacología: Editorial Universitaria, 956111514X. 2001. 